\title{
ANALISIS BIAYA DAN PRODUKTIVITAS PENYARADAN KAYU DENGAN \\ TRAKTOR CATERPILLAR D7G DI HUTAN ALAM TROPIKA BASAH PT \\ INHUTANI II, KALIMANTAN UTARA
}

\section{Cost Analysis and Productivity of Skidding in Natural Tropical Rain Forests of PT Inhutani II, North Kalimantan}

\author{
Muhdi \\ Program Studi Kehutanan Universitas Sumatera Utara \\ Jl. Nazir Alwi No.4, Komplek USU Medan, HP.0811657101, Indonesia \\ e-mail:muhdisyehamad@yahoo.com
}

Diterima 26-02-2015, direvisi 15-10-2015, disetujui 04-11-2015

\begin{abstract}
ABSTRAK
Tujuan penelitian adalah untuk mengetahui produktivitas dan biaya penyaradan kayu dengan traktor Catterpillar D7G dengan teknik reduced impact logging (RIL) dan konvensional di hutan alam tropika, Kalimantan Utara. Hasil penelitian menunjukkan produktivitas penyaradan kayu dengan traktor Catterillar D7G dengan teknik konvensional sebesar 21,78 m3/jam dan dengan teknik RIL sebesar 26,79 m3/jam. Biaya penyaradan dengan traktor Catterpillar D7G dengan teknik konvensional dan RIL masing-masing sebesar Rp 10.597,19/m3 dan Rp 8.695,39/m3.
\end{abstract}

Kata kunci: biaya, produktivitas, penyaradan, hutan alam tropis

\section{ABSTRACT}

The objective of this research was to findout the productivity and cost analysis of skidding by tractor of Catterpillar D7G by reduced impact logging (RIL) in natural forests. This research examined the extent of productivity and cost of crawler by mechanical skidding on skiddtrail in natural tropical forests, North Kalimantan. The research showed that the average productivity of skidding by tractor Catterpillar D7G on conventional plots were 21.78 m3/hour, while the average of productivity of skidding on RIL plots by tractor Catterpillar D7G were $26.79 \mathrm{m3} / \mathrm{hour}$. Total cost of skidding by tractor Catterpillar D7G on conventional and reduced impact logging (RIL) plots were IDR 10,597.19,- m-3 and IDR 8,695.39,-m-3, respectively.

Keywords: cost, productivity, skidding, natural tropical forest

\section{PENDAHULUAN}

Kegiatan pemanenan kayu memerlukan investasi yang sangat besar, sehingga harus diusahakan seefisien mungkin. Mengingat faktor biaya sangat menentukan, maka diperlukan perhitungan yang seksama terhadap biaya yang dikeluarkan untuk menghasilkan satu unit produksi.

Penyaradan merupakan suatu proses untuk mengangkut kayu bulat yang dihasilkan dari kegiatan penebangan di petak tebangan menuju ke tempat pengumpulan kayu yang pada umumnya menggunakan traktor penyarad. Pada hutan alam tropika dataran kering penyaradan kayu dilakukan dengan sistem mekanis yakni dengan menggunakan traktor.

Oleh karena itu upaya untuk menekan biaya penyaradan sangat penting. Efisiensi penyaradan dengan mengurangi waktu kerja tidak efektif dan hilang akan meningkatkan produktivitas penyaradan yang pada akhirnya mengurangi biaya-biaya yang tidak perlu. Tujuan penelitian ini adalah untuk mengetahui produktivitas dan biaya penyaradan kayu dengan traktor Catterpillar D7G di hutan alam tropika, Kalimantan Utara.

\section{METODOLOGI PENELITIAN}

Penelitian dilakukan di areal IUPHHK PT INHUTANI II, Malinau, Kalimantan Utara. Penelitian dilakukan pada petak RKT berjalan. Letak petak penelitian pemanenan kayu dengan teknik konvensional dan teknik RIL dibuat berdampingan pada areal petak tebang yang sama dengan keadaan kelerengan, tegakan, 
intensitas penebangan dan alat serta operator yang sama. Masing-masing mempunyai satu tempat pengumpulan kayu (TPN) yang melayani pemanenan kayu.

Waktu kerja penyaradan kayu adalah sebagai berikut: a) Waktu pembuatan tempat pengumpulan kayu (Tpn); b.) Waktu pembuatan jalan sarad; c.) Waktu penyaradan; d). Jarak sarad; e) Diameter dan panjang log; dan jumlah tenaga kerja. Waktu kerja penyaradan diukur dengan stopwatch, merupakan jumlah dari setiap waktu kerja masing-masing elemen kegiatan. Pengukuran waktu kerja menyarad kayu dilakukan pada tiga panjang jalan sarad, yaitu jarak dekat $(<250 \mathrm{~m})$, jarak sedang $(250-500 \mathrm{~m})$ dan jarak jauh (>750m).

Ulangan pengamatan waktu untuk setiap elemen adalah sebanyak 30 ulangan, dimana untuk setiap jarak sarad dilakukan 10 ulangan. Adapun elemen kerja penyaradan adalah sebagai berikut : a.) Berjalan kosong ke tempat kayu; b.) Memuat, meliputi persiapan memuat dan memuat kayu ke atas traktor; c). Menyarad; dan d) Membongkar, meliputi : membongkar kayu dan pengaturan kayu di Tpn.

Data sekunder yang dikumpulkan, yakni :
(1) harga alat, (2) biaya pemeliharaan, (3) masa pakai alat, (4) upah operator dan helper, (5) jam kerja per hari, (6) suku bunga dan (6) harga solar. Perhitungan volume batang kayu per sortimen dihitung dengan rumus Smalian; produktivitas penebangan/penyaradan kayu, dihitung dengan rumus ILO (1975); dan biaya dihitung dengan rumus (Elias, 1987).

\section{HASIL DAN PEMBAHASAN}

\section{A. Waktu Kerja Penyaradan}

Kegiatan penyaradan di IUPHHK PT Inhutani II menggunakan traktor Catterpillar D7G. Satu regu penyarad terdiri dari dua orang yakni operator dan pembantu operator. Dalam kegiatan penyaradan terdapat beberapa elemen kerja meliputi berjalan kosong yakni traktor menuju tempat tebangan, manuver alat di petak tebang, memasang pengait/sling, berjalan bermuatan yakni traktor menarik log menuju TPn, melepas pengait di TPn, serta manuver alat dan mengatur kayu di TPn. Hasil pengamatan waktu kerja penyaradan rata-rata yang diperlukan untuk menyarad kayu pada petak pemanenan kayu konvensional dan RIL dapat dilihat pada Tabel 1.

Tabel 1. Rata-rata waktu kerja penyaradan pada petak pemanenan kayu konvensional dan RIL

Table 1. Average of skidding work time in conventional and RIL plots

\begin{tabular}{llllll}
\hline & & \multicolumn{2}{c}{$\begin{array}{c}\text { Konvensional } \\
\text { (Conventional) }\end{array}$} & & RIL \\
\cline { 3 - 6 } $\begin{array}{l}\text { Nomor } \\
\text { (Number })\end{array}$ & $\begin{array}{l}\text { Elemen Kerja } \\
\text { (Work Element) }\end{array}$ & $\begin{array}{l}\text { Menit } \\
\text { (Minutes) }\end{array}$ & $\begin{array}{l}\text { Persen } \\
\text { (Percent) }\end{array}$ & $\begin{array}{l}\text { Menit } \\
\text { (Minutes) }\end{array}$ & $\begin{array}{l}\text { Persen } \\
\text { (Percent) }\end{array}$ \\
\hline 1. & Berjalan kosong & 6,81 & 32,35 & 5,88 & 32,04 \\
\hline 2. & Manuver alat di petak tebang & 1,37 & 6,49 & 1,03 & 5,61 \\
\hline 3. & Memasang pengait/sling & 1,05 & 5,00 & 1,09 & 5,94 \\
\hline 4. & Berjalan bermuatan & 8,27 & 39,29 & 7,50 & 40,92 \\
\hline 5. & Melepas pengait di TPn & 0,72 & 3,41 & 0,70 & 3,84 \\
\hline 6. & Manuver alat dan mengatur kayu di TPn & 1,63 & 7,73 & 1,41 & 7,68 \\
\hline 7. & Waktu hilang & 1,21 & 5,73 & 0,73 & 3,97 \\
\hline & Jumlah & 21,06 & 100,00 & 18,34 & 100,00 \\
\hline
\end{tabular}

Sumber: diolah dari data primer

Tabel 1 menyajikan rata-rata total waktu yang diperlukan untuk penyaradan kayu per trip pada petak pemanenan kayu konvensional sebesar 21,06 menit pada jarak sarad rata-rata 3,74 hm dan rata-rata volume kayu yang disarad 7,36 m3.
Pada petak pemanenan teknik RIL rata-rata total waktu yang diperlukan untuk penyaradan kayu per trip sebesar 18,34 menit pada jarak sarad rata-rata 3,69 hm dan rata-rata volume kayu yang disarad 7,60 m3. 
Diantarabeberapa elemenkerja dalam kegiatan penyaradan pada kedua petak pemanenan kayu dapat dilihat bahwa traktor menyarad bermuatan menuju TPn dan berjalan kosong menuju tempat tebangan memerlukan waktu kerja cukup lama. Pada petak pemanenan kayu konvensional elemen kerja traktor menyarad bermuatan menuju TPn dan berjalan kosong menuju petak tebang memerlukan waktu kerja terbesar masingmasing sebesar yakni sebesar 8,27 menit $(39,29$ $\%$ dan 6,81 menit $(32,35 \%)$ dari total waktu waktu menyarad per trip. Demikian halnya pada petak pemanenan kayu RIL dimana elemen kerja traktor menyarad bermuatan menuju TPn dan berjalan kosong memerlukan waktu kerja terbesar masing-masing sebesar 7,50 menit (40,92\%) dan 5,88 menit $(32,04 \%)$ dari total waktu menyarad per trip. Adapun rata-rata waktu kerja terkecil pada kedua petak pemanenan kayu konvensional dan RIL adalah melepas pengait di TPn masingmasing sebesar 0,72 menit $(3,41 \%)$ dan 0,70 $(3,84 \%)$ dari total waktu menyarad per trip.

Elemen kerja menyarad bermuatan dan berjalan kosong mempunyai waktu kerja yang paling tinggi dibandingkan dengan elemen kerja lainnya dalam kegiatan penyaradan. Waktu perjalanan kosong cukup tinggi pada petak pemanenan kayu konvensional karena saat traktor meuju kayu yang akan disarad, traktor harus membuat jalan sarad. Tingginya waktu traktor berjalan kosong menuju tempat tebangan dipengaruhi oleh jarak antara TPn dan kayu yang akan disarad, kerapatan tumbuhan bawah, kerapatan tegakan sepanjang jalan sarad serta kemiringan jalan sarad yang dilalui. Apabila jarak tempuh semakin jauh, vegetasi sepanjang jalan sarad rapat dan kemiringan jalannya naik maka waktu yang dibutuhkan menuju ke tempat tebangan semakin besar.

Dalam menghadapi vegetasi yang rapat traktor harus maju-mundur untuk membuat jalan sarad, berbeda dengan vegetasi yang jarang, traktor hanya berjalan menuju tempat tebangan. Keadaan kerapatan vegetasi di tempat yang diamati bervariasi, sehingga pada jarak yang lebih pendek tetapi vegetasinya rapat memerlukan waktu tempuh yang lebih lama dibandingkan dengan saat pertama kali menuju tempat tebangan, karena saat pertama traktor menuju tempat tebangan harus merintis jalan terlebih dahulu. Tingginya waktu kerja menyarad bermuatan dipengaruhi oleh jarak sarad, kemiringan jalan sarad, volume kayu yang disarad dan keterampilan operator.

Waktu kerja melepas muatan mempunyai waktu kerja terkecil. Hal ini dapat dimengerti karena melepas muatan prinsipnya hanya melepaskan kait dari kabel. Waktu kerja untuk mengaitkan kabel lebih tinggi dari waktu melepas muatan pada kedua petak pemanenan kayu konvensional dan RIL masing-masing sebesar 1,05 menit $(5,00 \%)$ dan 1,09 menit $(5,94 \%)$ dari total waktu penyaradan. Hal ini disebabkan mengaitkan muatan lebih sulit, terlebih pada posisi kayu yang berada di jurang atau lereng yang curam.

Besarnya waktu hilang dalam kegiatan penyaradan pada petak pemanenan kayu konvensional dan RIL masing-masing sebesar $5,73 \%$ dan 3,97 \% dari total waktu menyarad per trip. Waktu hilang yang terjadi dalam kegiatan penyaradan ini adalah waktu yang diperlukan memasang sling yang lepas/putus, memutar pisau, mencari kayu yang telah ditebang, dan waktu yang diperlukan untuk menunggu kayu dipotong karena bagian kayunya belum lepas (terpotong)

\section{B. Produktivitas dan Biaya Penyaradan}

Kegiatan penyaradan dalam penelitian ini menggunakan traktor Caterpillar D7G. Berdasarkan hasil perhitungan diperoleh bahwa produktivitas penyaradan kayu pada petak pemanenan kayu konvensional antara 11,74 m3/jam sampai dengan 38,30 m3/jam dengan rata-rata sebesar 21,78 m3/jam. Produktivitas penyaradan pada petak pemanenan kayu RIL antara 10,14 m3/jam sampai dengan 64,97 m3/ jam dengan rata-rata sebesar 26,79 m3/jam. Jarak sarad terpendek pada petak pemanenan kayu konvensional 1,64 hm dan terjauh 6,64 hm dengan jarak sarad rata-rata $3,74 \mathrm{hm}$. Pada petak pemanenan kayu RIL, jarak sarad terpendek 1,12 
$\mathrm{hm}$ dan terjauh $6,18 \mathrm{hm}$ dengan jarak sarad ratarata $3,69 \mathrm{hm}$.

Volume kayu yang disarad setiap rit pada petak pemanenan kayu konvensional berkisar antara 3,71 m3 sampai dengan 13,27 m3 dengan volume sarad rata-rata 7,36 $\mathrm{m} 3$ serta kecepatan penyaradan rata-rata $2,95 \mathrm{~km} / \mathrm{jam}$. Volume kayu yang disarad setiap rit pada petak pemanenan kayu RIL berkisar antara 3,89 $\mathrm{m} 3$ sampai dengan 13,61 m3 dengan volume sarad rata-rata 7,60 m3 serta kecepatan penyaradan rata-rata $3,97 \mathrm{~km} /$ jam.

Produktivitas penyaradan kayu pada petak pemanenan kayu konvensional lebih rendah. Hal ini diduga tingginya waktu tidak efektif. Waktu hilang yang terjadi dari total waktu rata-rata untuk mengerjakan satu pohon sebesar 1,21 menit $(5,73 \%)$ dan 0,73 menit $(3,97 \%)$ dari total ratarata waktu penebangan. Hal ini mencerminkan penggunaan waktu pada pemanenan kayu konvensional kurang efisien sehingga total waktu yang dibutuhkan untuk menyarad satu pohon menjadi tinggi, padahal prestasi kerja yang tinggi dapat diperoleh dengan cara meningkatkan waktu kerja efektif dan menekan waktu hilang.

Pembuatan rencana jaringan jalan sarad dapat mengurangi waktu hilang yang dapat dihindarkan. Tanpa pembuatan rencana jaringan jalan sarad, regu penyarad membutuhkan waktu untuk mencari pohon yang telah ditebang oleh regu penebang. Pembuatan rencana jaringan jalan sarad meningkatkan efisiensi waktu kerja penyaradan karena telah memperitmbangkan keadaan topografi, kerapatan tegakan, dan kondisi tanah serta potensi dan posisi pohon pohon (Elias, 1998).

Penggunaan jenis traktor ini memerlukan investasi yang besar. Biaya usaha traktor penyarad diperhitungkan dari komponen-komponen penyusun biaya usaha, yaitu biaya tetap alat, biaya variabel alat dan upah operator dalam satuan waktu. Berdasarkan hasil perhitungan diperoleh biaya total penyaradan pada petak pemanenan kayu konvensional dan RIL masing-masing sebesar Rp 10.597,19,-/m3 dan Rp 8.695,39,-/ m3. Biaya penyaradan pada petak pemanenan kayu konvensional dan RIL dapat dilihat pada Tabel 2.

Tabel 2. Biaya penyaradan kayu di areal IUPHHK PT Inhutani II

Table 2. Cost of skidding in IUPHHK PT Inhutani II areas

\begin{tabular}{lll}
\hline $\begin{array}{l}\text { Komponen Biaya } \\
\text { Cost Component })\end{array}$ & $\begin{array}{l}\text { Konvensional (Conventional) } \\
(\mathrm{Rp} / \mathrm{jam})\end{array}$ & $\begin{array}{l}\mathrm{RIL} \\
(\mathrm{Rp} / \mathrm{jam})\end{array}$ \\
\hline A. Biaya Usaha & & \\
\hline \multicolumn{1}{c}{ 1. Biaya tetap } & $40.059,65,-$ & $40.059,65,-$ \\
\hline 2. Biaya variabel & $173.604,34,-$ & $173.604,34,-$ \\
\hline 3. Upah & $17.142,86,-$ & $19.285,71,-$ \\
\hline B. Total biaya penyaradan & $230.806,90,-$ & $232.949,70,-$ \\
\hline C. Total biaya penyaradan per $\mathrm{m}^{3}$ & $10.597,19,-$ & $8.695,39,-$ \\
\hline
\end{tabular}

Sumber: diolah dari data primer

Hasil penelitian Barreto et al. (1998) menunjukkan bahwa produktivitas penebangan yang terencana $18 \%$ lebih rendah dibandingkan dengan yang tidak terencana walaupun produktivitas penyaradan dapat ditingkatkan 27 \%. Namun demikian hasil studi Holmes et al. (2002) di Para, Brasil menyatakan bahwa secara umum biaya pemanenan kayu teknik RIL lebih rendah dan lebih menguntungkan dibandingkan dengan pemanenan kayu konvensional. Keuntungan yang dicapai pada pemanenan kayu teknik RIL mencapai $35 \%$ hampir 2 kali lebih besar yang diteliti oleh Barreto et al. (1998). Perbedaan penghitungan keuntungan dan biaya sangat tergantung pada kondisi hutan, skala industri dan kondisi pasar. Boltz et al. (2003) menyatakan bahwa dari aspek analisis finansial pemanenan kayu teknik RIL lebih baik 
dibandingkan dengan pemanenan kayu secara konvensional apabila limbah pemanenan kayu diperhitungkan. Penerapan teknik RIL merupakan salah satu bagian dari pengelolaan hutan lestari yang berkaitan erat sebagai opportunity cost terhadap prasyarat silvikultur yang diperlukan dalam memelihara produktivitas dan ekosistem hutan. Hasil penelitian di Kongo dan Kamerun yang dilakukan de Blas dan Perez (2008) menyatakan bahwa pemanenan kayu teknik RIL akan diterima oleh para pengusaha jika benarbenar mendapatkan manfaat dari pasar melalui skema sertifikasi dan lebih mengikat.

\section{KESIMPULAN}

Produktivitas penyaradan kayu dengan traktor Catterpillar D7G pada petak pemanenan kayu konvensional lebih rendah, dimana produktivitas penyaradan kayu pada petak pemanenan kayu konvensional sebesar 21,78 $\mathrm{m}^{3} / \mathrm{jam}$ dan pada petak pemanenan kayu RIL rata-rata sebesar $26,79 \mathrm{~m}^{3} / \mathrm{jam}$. Hal ini diduga tingginya waktu tidak efektif. Penggunaan jenis traktor ini memerlukan investasi yang besar. Biaya usaha traktor penyarad diperhitungkan dari komponenkomponen penyusun biaya usaha, dimana biaya total penyaradan pada petak pemanenan kayu konvensional dan RIL masing-masing sebesar Rp $10.597,19,-/ \mathrm{m}^{3}$ dan $\mathrm{Rp} 8.695,39,-/ \mathrm{m}^{3}$.

\section{DAFTAR PUSTAKA}

Barreto P, Amaral P, Vidal E, \& Uhl C. (1998). Costs and benefits of forest management for timber production in eastern Amazonia. Forest Ecology and Management 108, 9-26.

De Blas DE, Perez MR. (2008). Prospects for reduced impact logging in Central African logging concessions. Forest Ecology and Management 256, 1509-1516.

Dykstra, D.P. \& R. Heinrich. (1996). Model Code of Forest Harvesting Practice. Food and Agriculture Organization of The United Nations. Rome.

Elias. (1987). Analisa Biaya Eksploitasi Hutan. Bogor : Fakultas Kehutanan IPB.

Elias. (1998). Reduced Impact Wood Harvesting in Tropical Natural Forest in Indonesia : ForestCase Study 11. Rome: Food and Agriculture Organization of the United Nation.

Elias. (1999). Reduced impact logging in the Indonesian selective cutting and planting system. Penerbit IPB Press. Bogor.

[ILO] International Labour Office. (1975). Penelitian Kerja dan Produktivitas. Jakarta : Erlangga.

Muhdi, Tito Sucipto \& Metrina Widyanti. (2006). Studi Produktivitas Penyaradan Kayu dengan Menggunakan Traktor Komatsu D70 LE di Hutan Alam. Jurnal Komunikasi Penelitian, 18 (3), 7-12.

Pinard, M.A., Barker, M.G., Tay, J. (2000). Soil disturbance and post-logging forest recovery on bulldozer paths in Sabah, Malaysia. Forest Ecology and Management, (130), 213-225.

Suparto, R.S. (1999). Bunga Rampai Pemanenan Kayu. Penyunting : Elias. IPB Press. Bogor. 
JURNAL Penelitian Ekosistem Dipterokarpa Vol. 1 No. 2, Desember 2015 : 63 - 68 